\title{
Improvement in the hygroscopicity of inorganic binder through a dual coating process
}

Hyun-Hee Choi ${ }^{1}$, Eun-Hee Kim ${ }^{1}$, Hye-Ju Lee ${ }^{1}$, Bong-Gu Kim ${ }^{1}$, Yeon-Gil Jung*,1, Jing Zhang ${ }^{2}$

${ }^{1}$ School of Materials Science and Engineering, Changwon National University, Changwon, Gyeongnam 51140, Republic of Korea

${ }^{2}$ Department of Mechanical and Energy Engineering, Indiana University-Purdue University Indianapolis, Indianapolis, IN 46202, USA

This is the author's manuscript of the article published in final edited form as: 


\section{Abstract}

The use of an anti-absorbent is proposed in this work to reduce the hygroscopicity of the inorganic binder in the casting mold, in which the anti-absorbent is coated on the mold prepared with an inorganic binder. Three types of polymers were used to select material with optimal water resistance. Polystyrene (PS) and polyvinyl alcohol (PVA) were used as a waterinsoluble polymer and water-soluble polymer, respectively. In addition, polyurethane (PU) prepolymer has intermediate properties between PS and PVA. PVA and PU prepolymer were used for comparative testing with PS. For this testing process, the prepared green body was dipped into a solution of inorganic binder precursor mixed with tetraethyl orthosilicate (TEOS, $\mathrm{SiO}_{2}$ precursor) and sodium methoxide ( $\mathrm{NaOMe}, \mathrm{Na}_{2} \mathrm{O}$ precursor), and then dipped into a solution of coating reagent after a drying process. Thus, these series of coating processes in a green body is called a dual coating process. Finally the sample was heat-treated at $1000{ }^{\circ} \mathrm{C}$ to generate a glass phase by an organic-inorganic conversion process. In the sample prepared with PS, the highest contact angle and a high firing strength were exhibited, independent of polymer concentration, while the sample coated with PVA showed lower green and firing strengths. When prepolymer, PU, was applied, the green strength was remarkably improved, showing lower firing strength compared with that of PS. The green and firing strengths were optimized through the dual coating process with PS. Moreover, the moisture-proof effect of the dual coating process was verified through the moisture steam test.

Keywords: Sand casting; Inorganic binder; Hygroscopicity; Dual coating process 


\section{Introduction}

In a conventional sand-casting process, the molds are manufactured by mixing ceramic materials and organic binders, and this process is widely used in the foundry industry because of the simple manufacturing process and low production cost [1-3]. However, it is difficult to form complex products since the organic binders are decomposed and defects in the mold are generated during casting at high temperatures [4-7]. To solve these problems, an organicinorganic binder conversion process has been proposed [8]. In this conversion process, the surface of the starting powder is coated with an organic binder and an inorganic binder is then coated on the organic binder. Thereafter, when the heat-treatment process is performed, the organic binder is volatilized and a void is formed; then, the inorganic binder that has been vitrified to have fluidity is replaced by the organic binder so the strength is expressed. Generally, the $\mathrm{Na}_{2} \mathrm{O}$ precursor $(\mathrm{NaOMe})$ and the silica precursor (TEOS) are used as the inorganic binder, and the coating is performed through hydrolysis and condensation (sol-gel reaction) [9-11].The, the $\mathrm{NaOH}$ converted from $\mathrm{NaOMe}$ modifies the network structure of the silica during the heat treatment. However, it absorbs water in the air before the heat treatment [12]. In particular, the absorption property of $\mathrm{NaOH}$ significantly affects firing strength due to the whirlwind vaporization phenomenon of the water faded by $\mathrm{NaOH}$ during the heat treatment.

Therefore, in this study, a new coating process using an anti-absorbent was applied to control the hygroscopicity of the inorganic binder. Three kinds of polymers were used: polystyrene (PS) as a water-insoluble polymer, polyvinyl alcohol (PVA) as a water-soluble polymer, and polyurethane (PU) prepolymer with intermediate properties $[13,14,15]$. In particular, PS and PVA were used to investigate the properties of the mold sample on the waterinsoluble and water-soluble polymers, respectively. In addition, PU prepolymer was used to evaluate the effect of a liquid polymer precursor instead of a hard-to-handle polymer like PVA. Furthermore, PU is less hydrophilic than PVA in molecular structure. The green body was 
coated with inorganic binders and then recoated with polymers, comprising a dual coating process. After coating with the polymers, the contact angle was measured to confirm the hydrophobic property the surface of the mold sample, and the strengths of samples before and after heat treatment were measured. Then, the moisture steam test was performed in order to confirm the water resistance of the mold sample in a high temperature and high humidity environments.

\section{Experimental procedure}

\subsection{Starting materials and sample preparation}

Ceramic bead (Cerabead; Itochu, Osaka, Japan) composed of a mullite $\left(3 \mathrm{Al}_{2} \mathrm{O}_{3} \cdot 2 \mathrm{SiO}_{2}\right)$ was used as a starting powder, and the green body was prepared through a compression process using the bead powder pre-treated with a resin-coated sand process. The inorganic binder was composed of tetraethyl orthosilicate (TEOS; Sigma-Aldrich Korea, Yong-in, Republic of Korea) as a silicon dioxide $\left(\mathrm{SiO}_{2}\right)$ precursor and sodium methoxide (NaOMe; Sigma-Aldrich Korea, Yong-in, Republic of Korea) as a sodium oxide $\left(\mathrm{Na}_{2} \mathrm{O}\right)$ precursor. As the water-insoluble polymer, PS (Sigma-Aldrich Korea, Yong-in, Republic of Korea) was used as an anti-absorbent. PS is relatively easy to handle and does not decompose at a dewaxing temperature $\left(200{ }^{\circ} \mathrm{C}\right)$ and has excellent mechanical properties $[13,14,15]$. Therefore, general-purpose PS represented by hydrophobic polymer was selected as an antiabsorbent. For, comparison, PVA (Sigma-Aldrich Korea, Yong-in, Republic of Korea) was also used, because it is a water-soluble binder.

PU prepolymer (Sigma-Aldrich Korea, Yong-in, Republic of Korea), having a relatively long chain polymer, was used to evaluate effect of water resistance on the antiabsorption and strength of the mold sample $[13,16]$. Experiments were performed according to the composition of the inorganic binders that showed the best properties in previous studies 
as a function of the viscosity of polymer solutions (PVA, PS, and PU prepolymer) [17, 18]. Table 1 shows the viscosity and molar concentrations with the type of polymer solution used in this work, and the molecular structure of the polymer used is shown in Fig. 1. The green body produced by the compression process (Jinsung Precision Metal Co., Ltd., Busan, Korea) was dipped into the solution of the inorganic binder and dried at $80{ }^{\circ} \mathrm{C}$ for $1 \mathrm{~h}$. It was then coated with the inorganic binder and redipped into the polymer solution followed by drying at $80{ }^{\circ} \mathrm{C}$ for $1 \mathrm{~h}$ or more. The dried sample was heat-treated at $1000{ }^{\circ} \mathrm{C}$ for $1 \mathrm{~h}$ to vitrify the inorganic binder. In this process, the inorganic binder moves by capillary action in the space created by the decomposition of the organic binder (resin). Thus, the glass phase is generated on the surface and interface of the particles. Figure 2 presents a schematic diagram of the preparation of the ceramic mold samples using each polymer solution. Each polymer solution was coated once.

\subsection{Characterization}

A tuning fork vibration-type viscometer (Model SV-10, AND, Gunpo, Korea) was used to measure the viscosity according to the concentration of the anti-absorbent. The solution with each anti-absorbent of $35 \mathrm{ml}$ was placed in a special container at room temperature and measured for about $15 \mathrm{~s}$. The functional groups of the anti-absorbent were analyzed using a Fourier-transform infrared spectrophotometer (FT/IR-6300, JASCO, Japan), and each sample was analyzed at wavelengths from 400 to $4000\left(\mathrm{~cm}^{-1}\right)$. The contact angle was then measured using a contact angle analyzer (Phoenix 300 Touch; Surface Electro Optics Co. Ltd., Suwon, Korea) after dropping the droplet onto the surface of the prepared sample. The microstructure of the mold sample was then examined using a scanning electron microscope (SEM, Model JSM-5610; JEOL, Tokyo, Japan) to observe the shape of the glass phase generated on the particles. Then, the fracture strengths of samples before and after heat treatment were 
measured using a universal testing machine (Instron 5566; Instron Corp., Norwood, MA, USA) in a three-point bending mode at a rate of $0.5 \mathrm{~mm} / \mathrm{min}$. The tests were performed at room temperature, and five runs were performed to determine the standard deviation of the fracture strength. The moisture steam test was conducted to confirm the hydrophobic property of the sample using dewaxing equipment (Jinsung Precision Metal Co., Ltd., Busan) at $170^{\circ} \mathrm{C}$ and $7 \mathrm{~kg} / \mathrm{cm}^{3}$ for $20-30 \mathrm{~min}$.

\section{Results and discussion}

The FT-IR spectra of the polymer materials, PVA, PU, and PS, are shown in Fig. 3. PVA has the specific characteristic peak of $\mathrm{OH}$ at $3428 \mathrm{~cm}^{-1}$ (Fig. 3(a)) [19-22]. In Fig. 3(b), the PU peak shows two characteristic bands at $2338 \mathrm{~cm}^{-1}$ and $1670 \mathrm{~cm}^{-1}$, which are assigned to $\mathrm{N}=\mathrm{C}=\mathrm{O}$ by the urethane group and the $\mathrm{C}=\mathrm{O}$ peak by the carboxyl group, respectively [23]. The aromatic peak of PS occurs at $1449 \mathrm{~cm}^{-1}$ (Fig. 3 (c)) [24]. Similarly, each polymer shows unique molecular characteristics with exclusive peaks. In addition, in PVA, the OH group is present in every two carbon atoms, which has a large hydrophilic property. However, the urethane group in the PU prepolymer is less hydrophilic than PVA since it has one urethane group per 1000 molecular weight (Fig. 1) [25].

The molar concentration of each polymer solution and viscosity are shown in Table 1. Among the three polymers, PS and PVA in the solid phase dissolved in benzene and water, respectively, and PU was diluted in water. Therefore, the molar concentration of PVA is high. In other words, the PU prepolymer has a hydrophilic property while the PU polymer is a waterinsoluble polymer due to the NCO-functional group remaining in the middle of the chain. However, the hydrophilicity of PU should be lower than the PVA with a OH-group per monomer. The contact angle was measured with water droplets to investigate the effect of polymers used for the protection of the inorganic binder from the moisture in the air, and the 
results are shown in Fig. 4. Overall, as the viscosity of the polymer solution increased, a high contact angle was measured by the high concentration of solutes. In addition, PS with a hydrophobic property naturally showed the highest contact angle, despite the low molar concentration. In addition, the PU prepolymer showed a higher contact angle than PVA caused by the relatively low hydrophilicity given the molecular structure. As a result, the hydrophobic effect of the mold sample coated with polymer was highest in the PS and lowest in PVA.

To confirm the hydrophobic effect of the applied polymers, the green and firing strengths of the samples prepared according to the type and concentration of the polymer were measured (Fig. 5). The results show that the strengths of sample prepared by the conventional process were about 6 and $10 \mathrm{MPa}$ before and after heat treatment, respectively. However, when the PVA was applied, the green and firing strengths of the samples showed lower values than those by the conventional process, independent of the concentration of PVA. The lower strengths resulted from the hydrophilicity of the sample being further increased by coating the PVA on the surface of the green body. The inorganic binder is present as $\mathrm{SiO}_{2}$ and $\mathrm{NaOH}$ after drying process. $\mathrm{NaOH}$ is dissolved into the PVA solution because of its highly hydrophilic property. And then, the water entrapped by the PVA rapidly vaporizes during the heat treatment and adversely affects the conversion of the inorganic binder to the glass phase. This is because lowering the $\mathrm{Na}$ content increases the melting point of the glass which results in reducing the glass transition efficiency at $1000{ }^{\circ} \mathrm{C}$. Therefore, as the concentration of the PVA solution increased, the firing strength gradually decreased. In the mold sample prepared with PS, the green and firing strengths were increased due to the higher hydrophobicity of PS compared with that of PVA and the conventional process, which showed the highest firing strength. In addition, the strengths were slightly increased with an increased concentration of PS within an error range [14]. The maximum green and firing strengths were determined to be $7.5 \pm 0.5$ and $13.0 \pm 1.6 \mathrm{MPa}$. As a result, in the case of the sample prepared with the PU prepolymer, the 
green strength was remarkably increased, showing the highest value of $13.0 \pm 0.9 \mathrm{MPa}$ in sample III. This result means that the green strength is affected more by the entanglement between the chains than by the molecular property of the polymer [26-28]. However, the firing strength was only slightly improved due to the water-soluble property of the PU prepolymer, with the maximum strength of $8.4 \pm 0.5 \mathrm{MPa}$ in sample III. The strengths were also modestly increased with an increased concentration of PU prepolymer. As a result, the polymer with a hydrophobic nature is efficient in improving the firing strength due to the increased conversion efficiency to the glass phase of the inorganic binder during heat treatment.

Based on the results of these experiments, the coating process that combined PS and PU was applied to improve the green and firing strengths (Fig. 2, process D). The process applied in this work is a dual process because it uses an inorganic binder and a polymer. Therefore, even if two polymers of PU and PS are used, process D is also regarded as a dual process. The contact angle and strength were then measured for the sample prepared through process D (Fig. 6). The sample showed a slightly higher contact angle (Fig. 6(a)) than that using a single polymer (Fig. 4), indicating that the hydrophobic effect of the sample prepared with the double polymer was better increased. The PS and PU coating layers played the role as an anti-absorbent, so the hydrophobic effect was increased with increasing the times of coating. The green and firing strengths were determined to be $11.7 \pm 0.8$ and $11.5 \pm 1.6 \mathrm{MPa}$, respectively. Therefore, both strengths could be optimized using the combined polymers, although the strengths were slightly lower than the green strength of the PU prepolymer and the firing strength of the PS.

To investigate the relationship between the strength and the microstructure, the fracture surfaces of the samples with the highest polymer concentration (sample type III) were observed (Fig. 7). In the thickness and range of the glass phase generated at the interface of particles (dotted arrows), the sample coated with PVA with the lowest firing strength had relatively thin 
thickness and narrow range compared with other samples. In addition, in the case of PS with the highest firing strength, the sample had a higher thickness and the glass phase was uniformly formed, with the formation of the glass phase being clearly visible in the microstructure (Fig. 7 (b)). When PU was single-coated, the reaction layer was thicker than PVA, but relatively thinner and narrower compared with that of PS, resulting in intermediate firing strength (Fig. 7 (c)). The results also show that the reaction layer was considerably wide in the case of the combined coating with PS and PU, but the firing strength was lower than that of PS because the glass phase did not uniformly form on the surface (solid arrows) as PS (Fig. 7 (d)).

The moisture steam test using the dewaxing equipment is shown in Fig. 8, confirming the hydrophobic effect of the samples (sample type III) prepared through processes $A, B, C$, and D. The samples remained without shape variation despite being in relatively severe environments. However, as shown in the results of the fracture strength, the strength of the sample prepared by process $\mathrm{C}$ was reduced and application would be difficult in the actual casting process because the mold requires the strength to withstand the self-weight of the molten melt during the casting. Therefore, using the composite coating process with PS and the PU prepolymer is preferable to increase the moisture absorption effect and the strength of the casting mold.

\section{Conclusions}

A dual coating process that recoats the polymer on the inorganic binder was developed to reduce the hygroscopicity of the inorganic binder, which adversely effects strength by decomposing the inorganic binder during heat treatment. We used three types of polymersPVA as a water-soluble polymer, PS as a water-insoluble polymer, and PU prepolymer as a precursor - to improve the hydrophobic effect of the mold. The sample prepared using PS showed the highest hydrophobic effect and that using PVA showed the lowest, as proven by the 
contact angle measured. This effect is due to the difference between the hydrophobicity and hydrophilicity of PS and PVA molecules, respectively. In addition, with respect to fracture strength, the sample coated with PS showed the highest firing strength due to the reduced hygroscopicity. However, in terms of green strength, the sample coated with PU prepolymer showed the highest strength, indicating that the green samples are more affected by the entanglement between chains. In the coating process using combined polymers of PU prepolymer and PS, reasonable green and firing strengths were obtained to produce a desirable casting mold. In addition, even if the mold is stored for a predetermined time before heat treatment, the green and firing strengths can be maintained with respect to moisture.

\section{Acknowledgments}

This work was supported by the Korea Institute of Energy Technology Evaluation and Planning (KETEP) and the Ministry of Trade, Industry \& Energy (MOTIE) of the Republic of Korea (No. 20172020108530), by the "Human Resources Program in Energy Technology" of KETEP and MOTIE of the Republic of Korea (No. 20194030202450), and by grants (NRF2016R1D1A3B03934054) from National Research Foundation (NRF) of Korea funded by the Korean Government. 


\section{References}

[1] C. Saikaew, S. Wiengwiset, Optimization of molding sand composition for quality improvement of iron castings, Appl. Clay Sci. $67 \quad$ (2012) 2631. http://doi.org/10.1016/j.clay.2012.07.005.

[2] Y.A. Meng, B.G. Thomas, Modeling transient slag-layer phenomena in the shell $/ \mathrm{mold}$ gap in continuous casting of steel, Metall. Mater. Trans. B 34B (2003) 707-725. http://doi.org/10.1007/s11663-003-0041-X

[3] M. Şimşir, L.C. Kumruoğlu, A. Özer, An investigation into stainless-steel/structurealloy-steel bimetal produced by shell mold casting, Mater. Des. 30 (2009) 264-270. http://doi.org/10.1016/j.matdes.2008.04.074

[4] J. Jiang, X.Y. Liu, Dimensional variations of castings and moulds in the ceramic mould casting process mater, J. Mater. Process. Technol. 189 (2007) 247-255. http://doi.org/10.1016/j.jmatprotec.2007.01.030

[5] E.H. Kim, G.H. Cho, Y.S. Oh, Y.G. Jung, Development of a high-temperature mold process for sand casting with a thin wall and complex shape, Thin Solid Films 620 (2016) 70-75. http://doi.org/10.1016/j.tsf.2016.08.069.

[6] E.H. Kim, W.R. Lee, Y.G. Jung, C.S. Lee, A new binder system for preparing high strength inorganic molds in precision casting, Mater. Chem. Phys. 126 (2011) 344-351. https://doi.org/10.1016/j.matchemphys.2010.11.015.

[7] Y.W. Dong, X.L. Li, Q. Zhao, J. Yang, M. Dao, Modeling of shrinkage during investment casting of thin-walled hollow turbine blades, J. Mater. Process. Technol. 244 (2017) 190-203. http://doi.org/10.1016/j.jmatprotec.2017.01.005.

[8] H. Saridkmen, N. Kuskonmaz, Properties of ceramic casting molds produced with two different binders, Ceram. Inter. 31 (2005) 873-878. http://doi.org/10.1016/j.ceramint. 
2004.10.004.

[9] J.L. Gurav, A.V. Rao, A.P. Rao, D.Y. Nadargi, S.D. Bhagat, Physical properties of sodium silicate based silica aerogels prepared by single step sol-gel process dried at ambient pressure, J. Alloys Compd. 476 (2009) 397-402. http://doi.org/10.1016 /j.jallcom.2008.09.029.

[10] M. Anbia, M. Lashgari, Synthesis of amino-modified ordered mesoporous silica as a new nano sorbent for the removal of chlorophenols from aqueous media, Chem. Eng. J. 150 (2009) 555-560. http://doi.org/10.1016/j.cej.2009.02.023.

[11] W. Xue, A. Bandyopadhyay, S. Bose, Mesoporous calcium silicate for controlled release of bovine serum albumin protein, Acta Biomater. 5 (2009) 1686-1696. http://doi.org/10.1016/j.actbio.2009.01.012.

[12] K. Erich, L. Wolfgang, G. Hermann, The color change in $\mathrm{CO}_{2}$ absorbents on drying: An in vitro study using moisture analysis, Anesth. Analg. 97 (2003) 151-155. http://doi.org/10.1213/01.ane.0000066264.64544.dc.

[13] W.D. Callister, D.G. Rethwisch, Materials Science and Engineering, $8^{\text {th }}$ ed., Wiley, New York, 2009.

[14] G.O. Schulz, R.Milkovich, Graft polymers with macromonomers. I. Synthesis from methacrylate-terminated polystyrene, J. Appl. Polym. Sci. 27 (1982) 4773-4786. http://doi.org/10.1002/app.1982.070271222.

[15] N. Hasegawa, H. Okamoto, M. Kawasumi, A. Usuki, Preparation and mechanical properties of polystyrene-clay hybrids, J. Appl. Polym. Sci. 74 (1999) 3359-3364. https://doi.org/10.1002/(SICI)1097-4628(19991227)74:14<3359::AID-APP9>3.0.C $\mathrm{O} ; 2-2$

[16] G.S. Freeland, Castable thermosetting polyurethane polymer having improved heat 
stability, United States Patent (1992) No. 5130404. https://patents.google.com /patent/US5441808A/en.

[17] V. Francis, P.K. Jain, Experimental investigations on fused deposition modelling of polymer-layered silicate nanocomposite, Virtual. Phys. Prototyp. 11 (2016) 109-121. https://doi.org/10.1080/17452759.2016.1172431.

[18] E.H. Kim, Y.G. Jung, J.H. Lee, Development of a new coating system for the high functional mold in thin-wall casting, Mater. Today: Proceedings 1 (2014) 55-69. https:// doi.org/10.1016/j.matpr.2014.09.013.

[19] Alireza Kharazmi et al., Structural, optical, opto-thermal and thermal properties of ZnSPVA nanofluids synthesized through a radiolytic approach, Beilstein J. Nanotech. 6 (2015) 529-536. https://doi.org/10.3762/bjnano.6.55.

[20] N.V. Bhat, M.M. Nate, M.B. Kurup, V.A. Bambole, S. Sabharwal, Effect of gammaradiation on the structure and morphology of polyvinyl alcohol films, Nucl. Instrum. Methods Phys. Res., Sect. B 237 (2005) 585-592. https://doi.org/10.1016/j.nimb. 2005.04.058.

[21] J. Lee, T. Isobe, M. Senna, Preparation of ultrafine $\mathrm{Fe}_{3} \mathrm{O}_{4}$ particles by precipitation in the presence of PVA at high pH, J. Colloid. Interf. Sci. 177 (1996) 490-494. https://doi.org/10.1006/jcis.1996.0062.

[22] I. Omkaram, R. Chakradhar,J. L. Rao, EPR, optical, infrared and Raman - studies of $\mathrm{VO}^{2+}$ ions in polyvinylalcohol films Physica B 388 (2007) 318-325. https://doi.org/j.physb.2006.06.134.

[23] Fernanda Oliveira Vieira da Cunha et al., Study of Castor Oil Polyurethane Poly(Methyl Methacrylate) Semi-Interpenetrating Polymer Network (SIPN) Reaction Parameters Using a 23 Factorial Experimental Design, Mater. Res. 7 (2004) 539-543. 
http://dx.doi.org/10.1590/S1516-14392004000400006.

[24] Esmaeil Biazar, Cell engineering: nanometric grafting of poly-N-isopropylacrylamide onto polystyrene film by different doses of gamma radiation, Int. J. Nanomed. 5 (2010) 549-556. https://doi.org/10.2147/IJN.S8269.

[25] Ciobanu, C., Han, X., Cascaval, C. N., Guo, F., Rosu, D., Ignat, L., \& Moroi, G., Influence of urethane group on properties of crosslinked polyurethane elastomers, J. Appl. Polym. Sci. 87(11) (2003) 1858-1867. https://doi.org/10.1002/app.11509

[26] H. Tobushi, H. Hara, E. Yamada, S. Hayashi, Thermomechanical properties in a thin film of shape memory polymer of polyurethane series, Smart Mater. Struct. 5 (1996) 483-491. https://doi.org/10.1117/12.232168.

[27] C. Ciobanu, M. Ungureanu, L. Ignat, D. Ungureanu, V.I. Popa, Properties of ligninpolyurethane films prepared by casting method, Indust. Crop. Prod. 20 (2004) 231-241 .https://doi.org/10.1016/j.indcrop.2001.04.024.

[28] M. Potoczek, M. Heneczkowski, M. Oleksy, A new polyurethane binder providing high green strength of dry-pressed alumina, Ceram. Inter. 29 (2003) 259-264. https://doi.org/10.1016/S0272-8842(02)00113-X. 


\section{Table caption}

Table 1. Viscosity and molar concentration with the three types of polymers

\section{Figure captions}

Fig. 1. Molecular structure of polymers used in this work. (a) PVA, (b) PU, and (c) PS.

Fig. 2. Schematic diagram of coating processes using the three polymers for improving the hygroscopicity of the inorganic binder.

Fig. 3. FT-IR spectra of the three polymers. (a) PVA, (b) PU, and (c) PS.

Fig. 4. The contact angle with the three types and concentrations of polymers. (a) PVA, (b) PS, and (c) PU. Each number (I, II, III) indicates the molar concentration of polymer sample types shown in Table 1.

Fig. 5. Fracture strength of the three polymers. (a) PVA, (b) PS, and (c) PU. Dotted and solid lines respectively indicate strength values before and after heat treatment of samples prepared through the conventional process without anti-absorbent.

Fig. 6. Contact angle and fracture strength of samples prepared through process D. (a) Contact angle and (b) fracture strength.

Fig. 7. Fracture images after the strength test and microstructures of samples prepared with the four processes: (a) process A, (b) process B, (c) process C, and (d) process D. Each number indicates the fracture surface image before and after heat treatment. The top and bottom microstructures in each number are the inside and the edge of samples, respectively. Dotted and solid arrows indicate the glass phase generated at the interface of particles and on the surface of particles, respectively.

Fig. 8. Moisture-proof test in the dewaxing condition for sample type III prepared with processes A, B, C and D shown in Fig. 1.: (a) Dewaxing apparatus, (b) sample with process A, 
(c) sample with process $B$, (d) sample with process $C$, and (e) sample with process D. 
Table 1 . Viscosity and molar concentration with the three types of polymers

\begin{tabular}{|c|c|c|c|c|}
\hline Type of polymer & $\begin{array}{l}\text { Sample } \\
\text { type }\end{array}$ & $\begin{array}{c}\text { Solvent } \\
\text { wt\%(mol\%) }\end{array}$ & $\begin{array}{c}\text { Polymer } \\
\text { wt\%(mol\%) }\end{array}$ & $\begin{array}{l}\text { Viscosity } \\
(\mathbf{m P a} \cdot \mathbf{S})\end{array}$ \\
\hline \multirow{3}{*}{$\begin{array}{l}\text { A. Polyvinyl alcohol } \\
\text { (PVA) }\end{array}$} & I & 98.9 (99.98) [water] & $1.04\left(1.79 \times 10^{-4}\right)$ & 1.37 \\
\hline & II & 97.9 (99.96) [water] & $2.05\left(3.63 \times 10^{-4}\right)$ & 3.13 \\
\hline & III & 95.9 (99.93) [water] & $4.01\left(7.25 \times 10^{-4}\right)$ & 10.5 \\
\hline \multirow{3}{*}{$\begin{array}{l}\text { B. Polystyrene } \\
\text { (PS) }\end{array}$} & $\mathrm{I}$ & 96.62 (99.98) [benzene] & $3.38(0.02)$ & 3.76 \\
\hline & II & 93.46 (99.96) [benzene] & $6.54(0.04)$ & 10.6 \\
\hline & III & 87.72 (99.93) [benzene] & $12.28(0.07)$ & 29.7 \\
\hline \multirow{3}{*}{$\begin{array}{l}\text { C. Polyurethane (PU) } \\
\text { prepolymer }\end{array}$} & I & 50 (95.19) [water] & $50(4.81)$ & 11.5 \\
\hline & II & 40 (92.89) [water] & $60(7.11)$ & 23.0 \\
\hline & III & 33.33 (91.13) [water] & $66.67(8.87)$ & 49.2 \\
\hline
\end{tabular}


$\overbrace{\mathrm{HO}}$

(a) PVA

$$
\mathrm{R}-\mathrm{NH}-\stackrel{\mathrm{O}}{\mathrm{C}}-\mathrm{O}-\mathrm{R}^{\prime}
$$

(b) PU

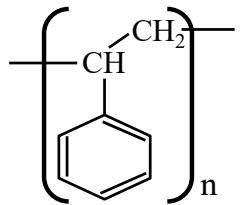

(c) PS

Fig. 1. Molecular structure of polymers used in this work. (a) PVA, (b) PU, and (c) PS.

[Process A]

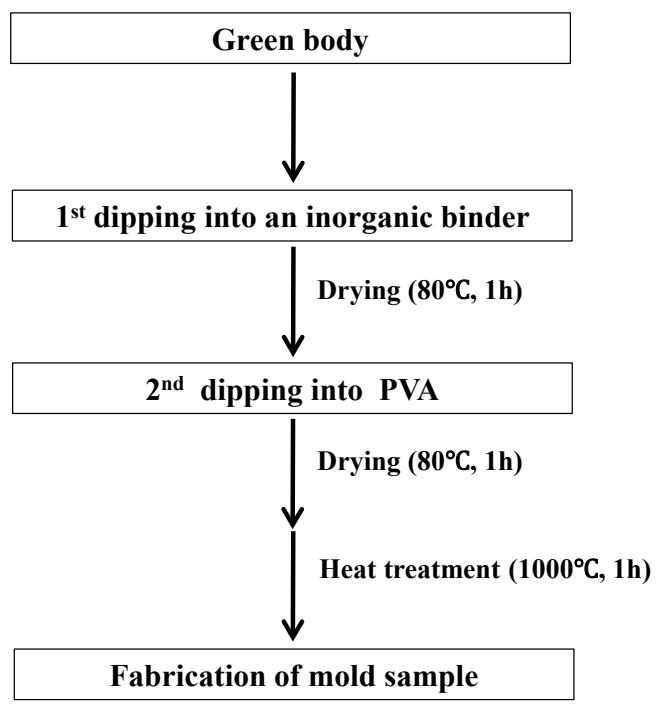

[Process C]

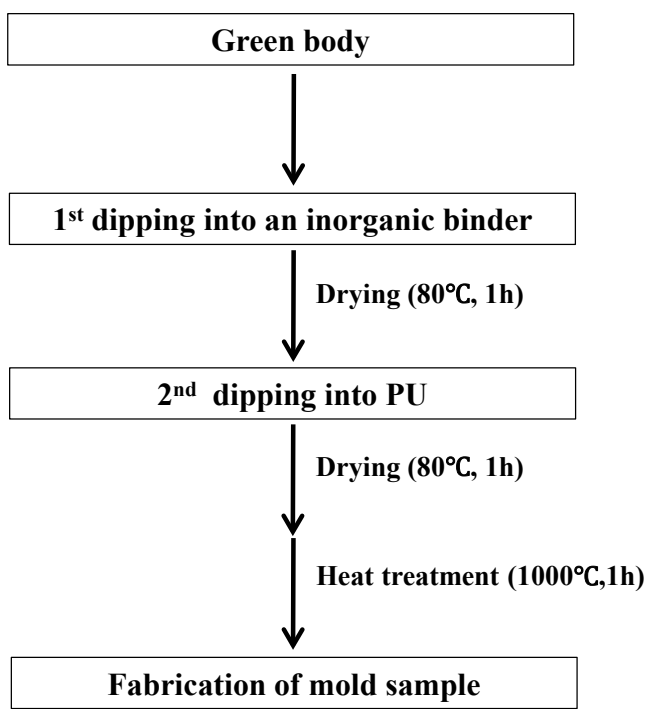

[Process B]

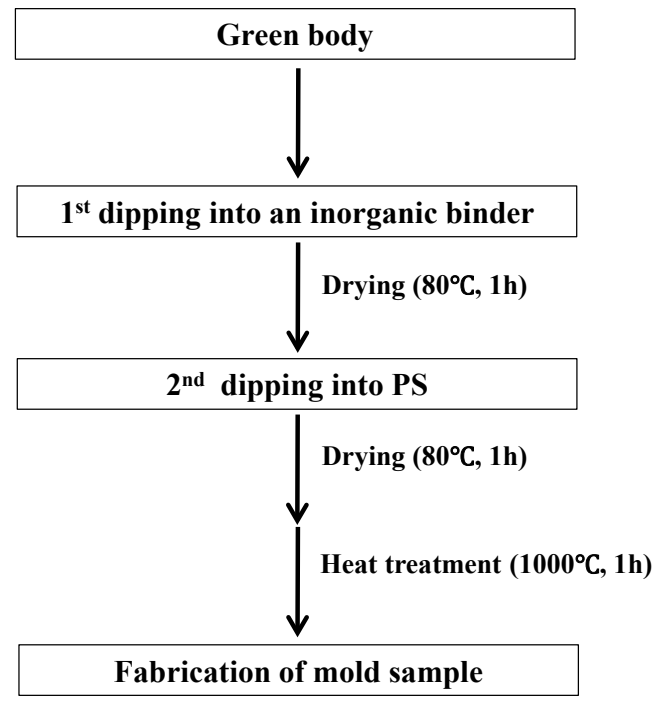

[Process D]

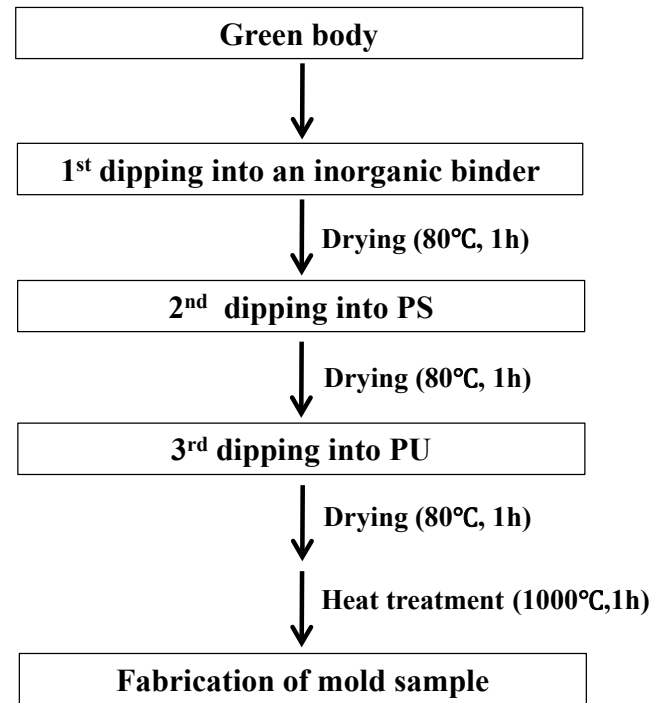


Fig. 2. Schematic diagram of coating processes using the three polymers for improving the hygroscopicity of the inorganic binder.

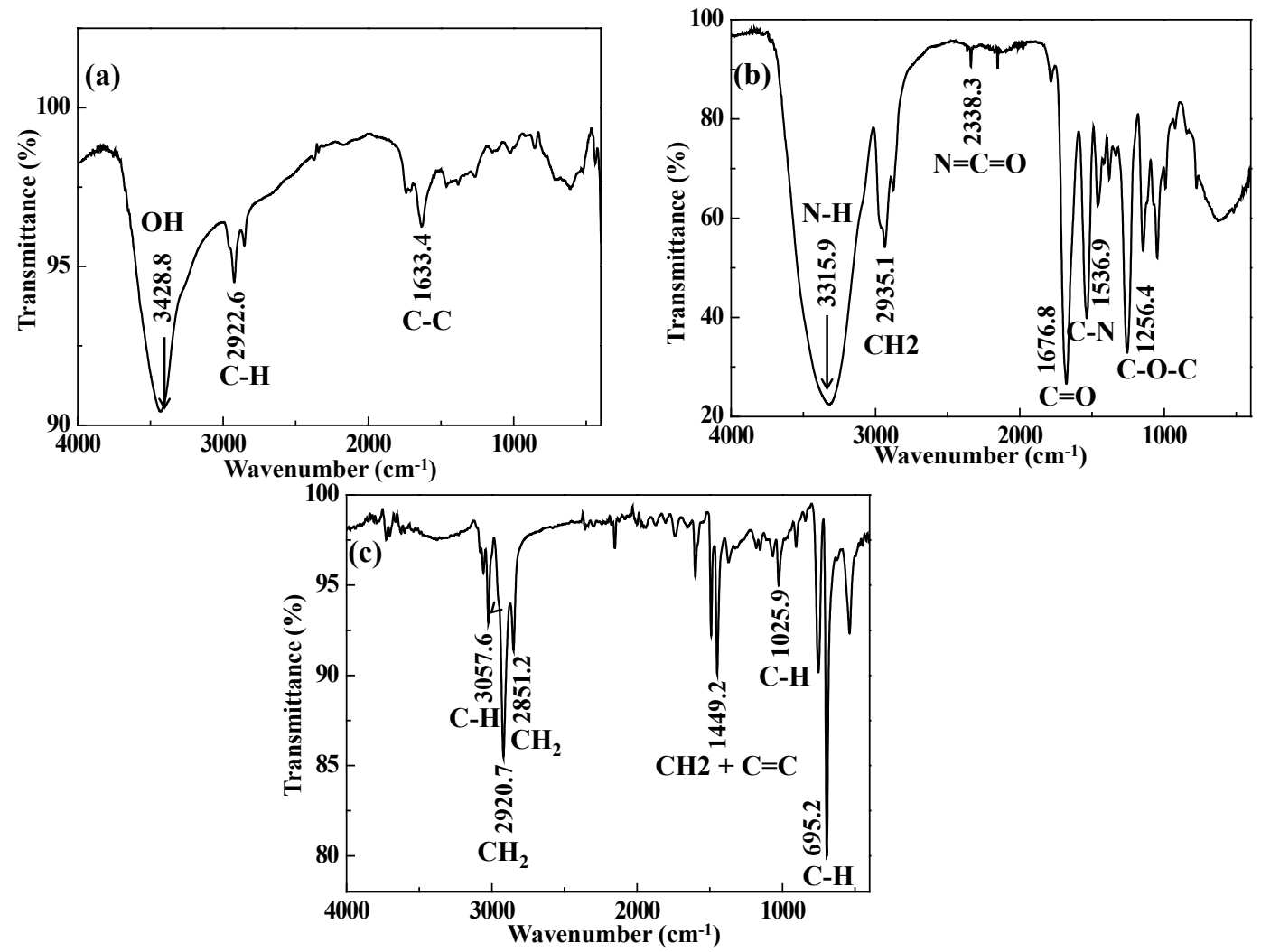

Fig. 3. FT-IR spectra of the three polymers. (a) PVA, (b) PU, and (c) PS. 

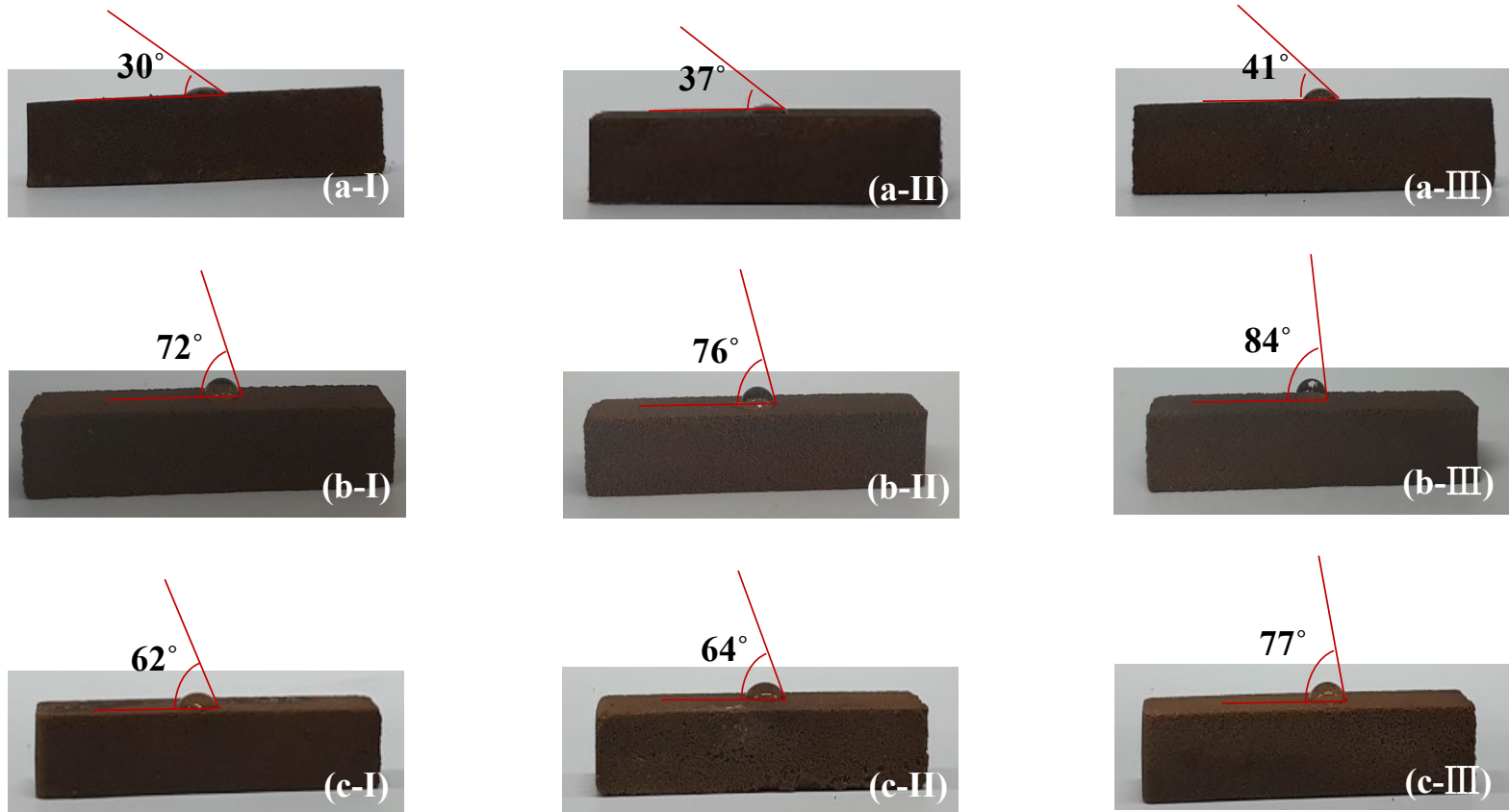

Fig. 4. The contact angle with the three types and concentrations of polymers. (a) PVA, (b) PS, and (c) PU. Each number (I, II, III) indicates the molar concentration of polymer sample types shown in Table 1.
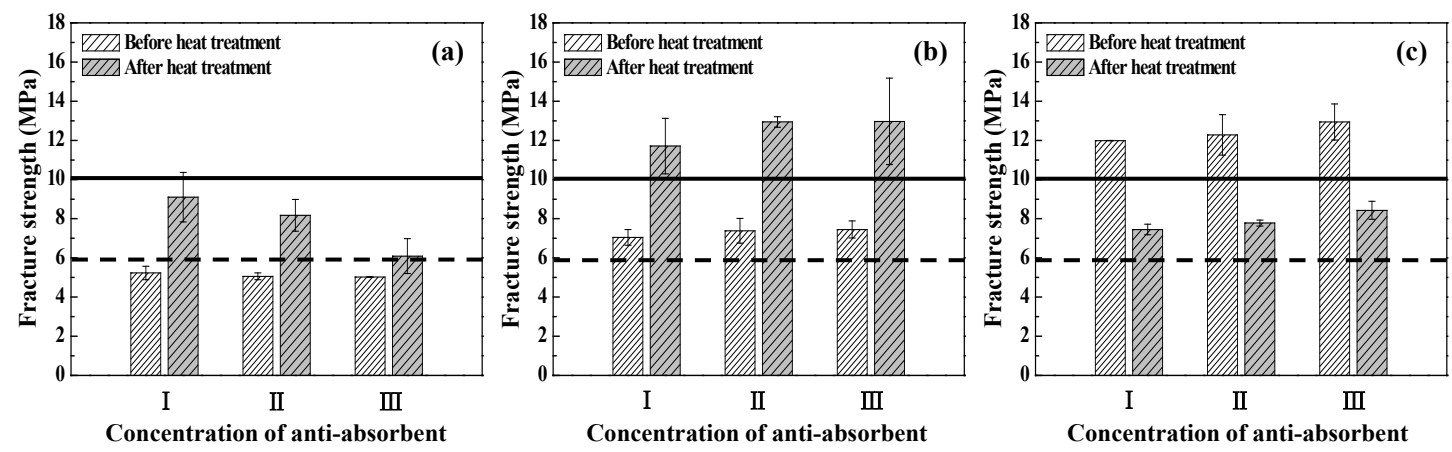

Fig. 5. Fracture strength of the three polymers. (a) PVA, (b) PS, and (c) PU. Dotted and solid lines respectively indicate strength values before and after heat treatment of samples prepared through the conventional process without anti-absorbent. 


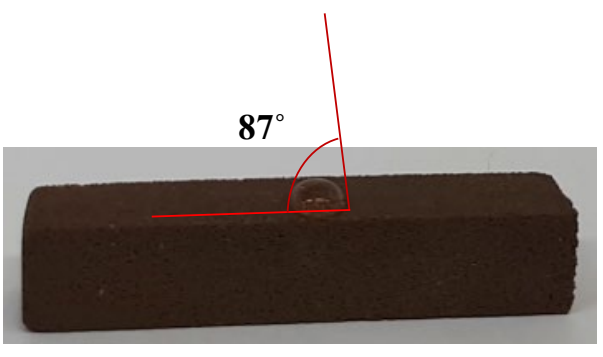

(a)

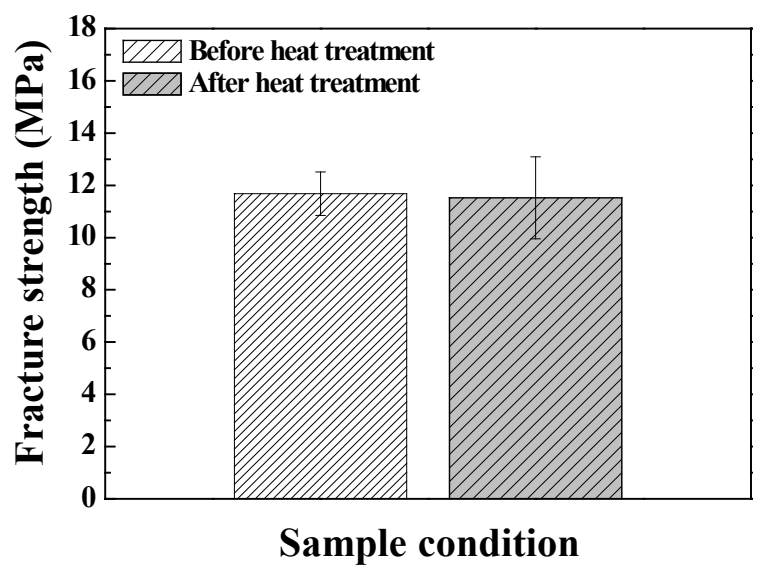

(b)

Fig. 6. Contact angle and fracture strength of samples prepared through process D. (a) Contact angle and (b) fracture strength.
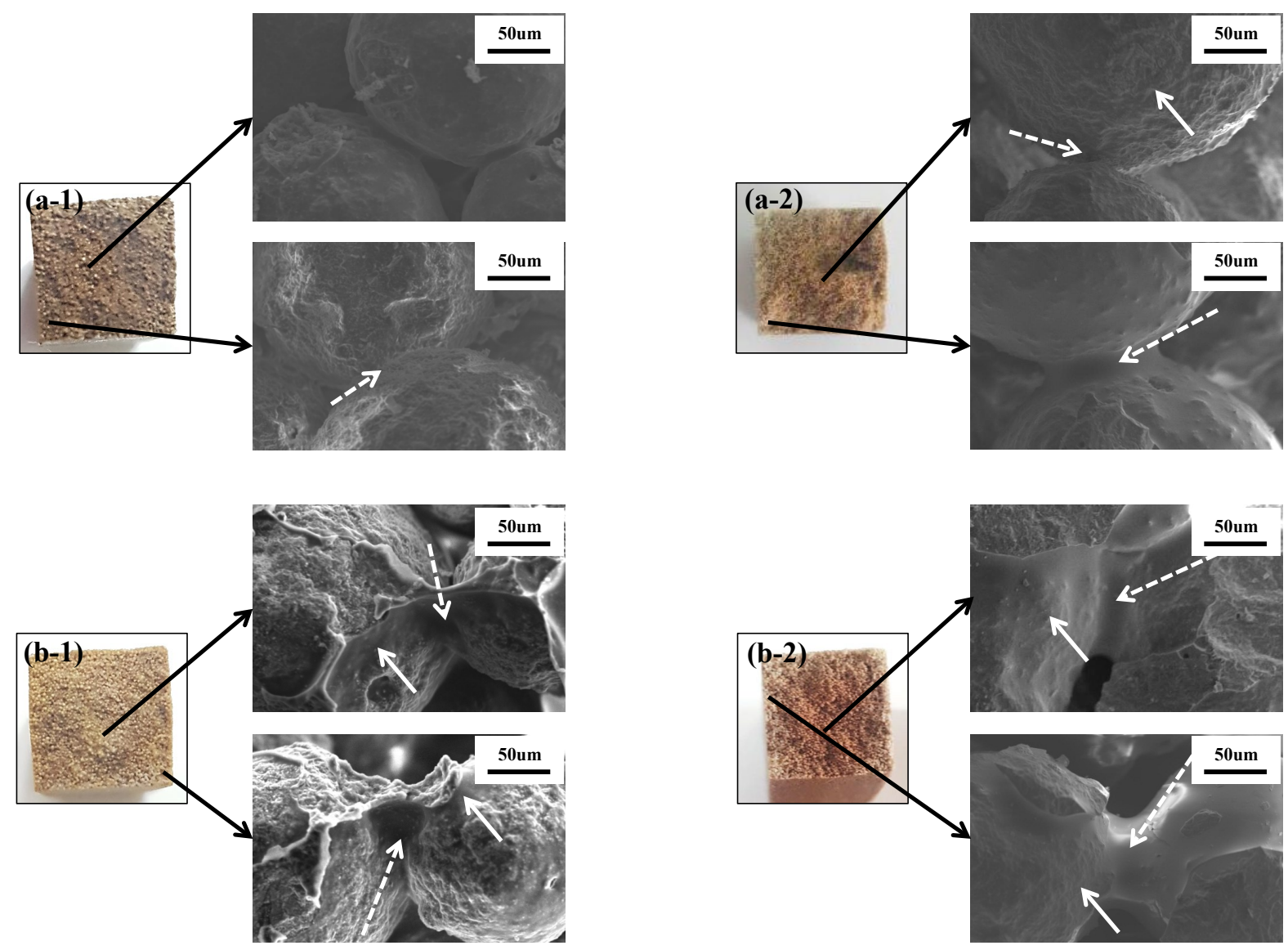

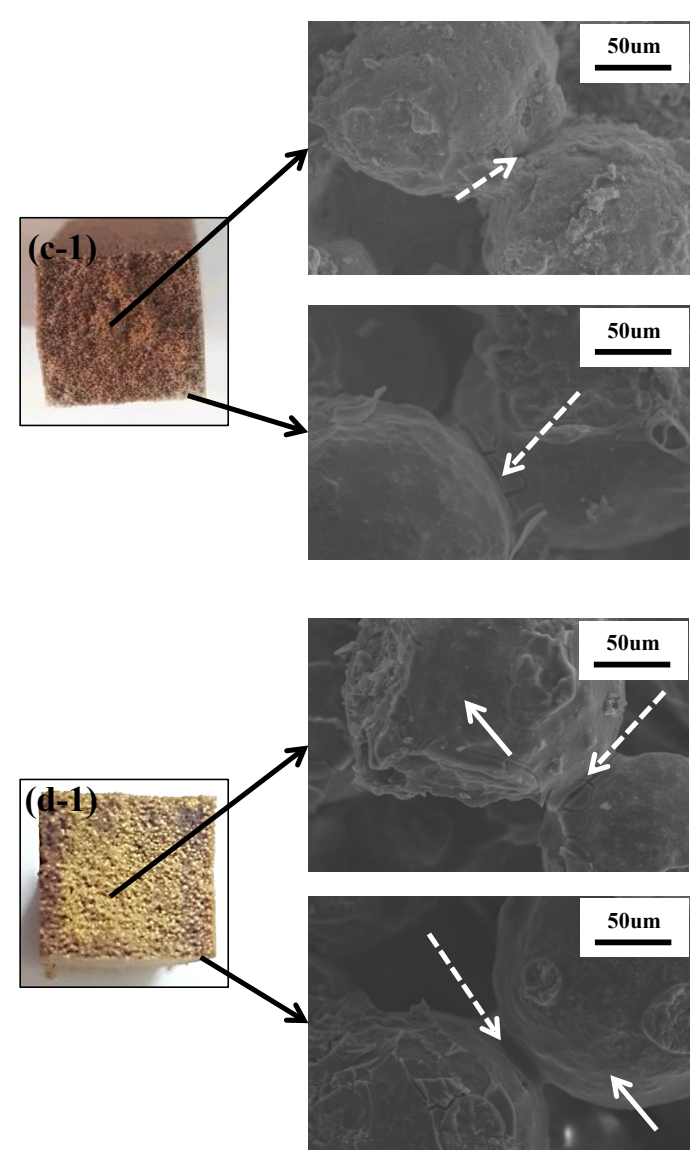
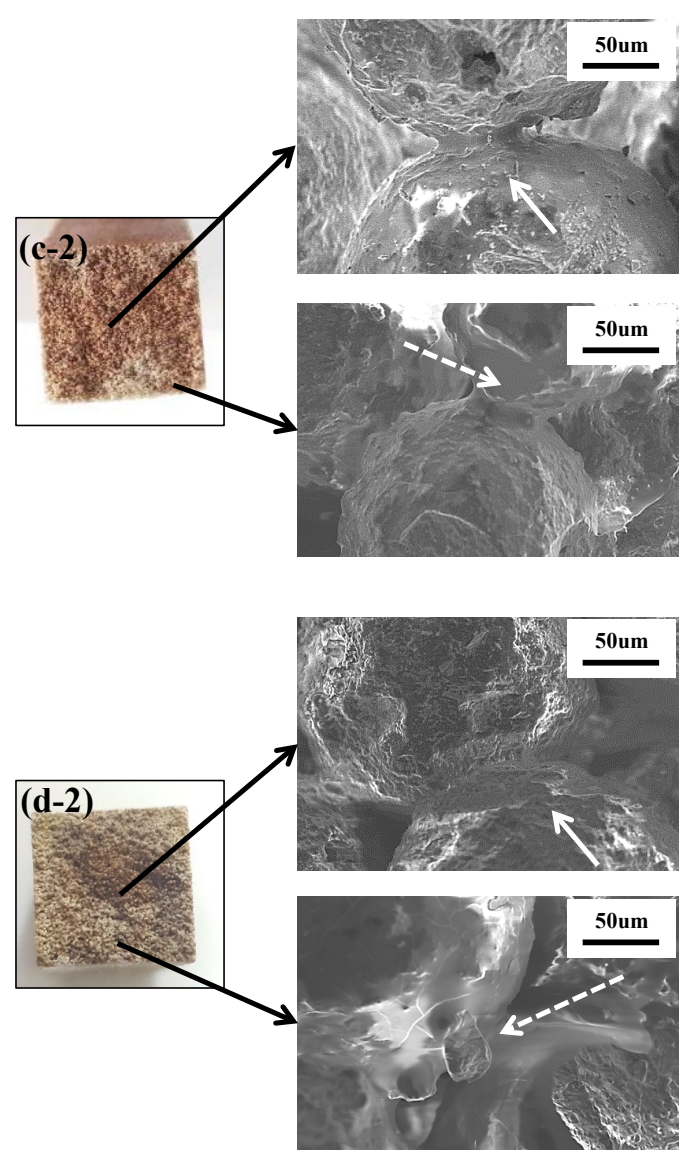

Fig. 7. Fracture images after the strength test and microstructures of samples prepared with the four processes: (a) process A, (b) process B, (c) process C, and (d) process D. Each number indicates the fracture surface image before and after heat treatment. The top and bottom microstructures in each number are the inside and the edge of samples, respectively. Dotted and solid arrows indicate the glass phase generated at the interface of particles and on the surface of particles, respectively. 


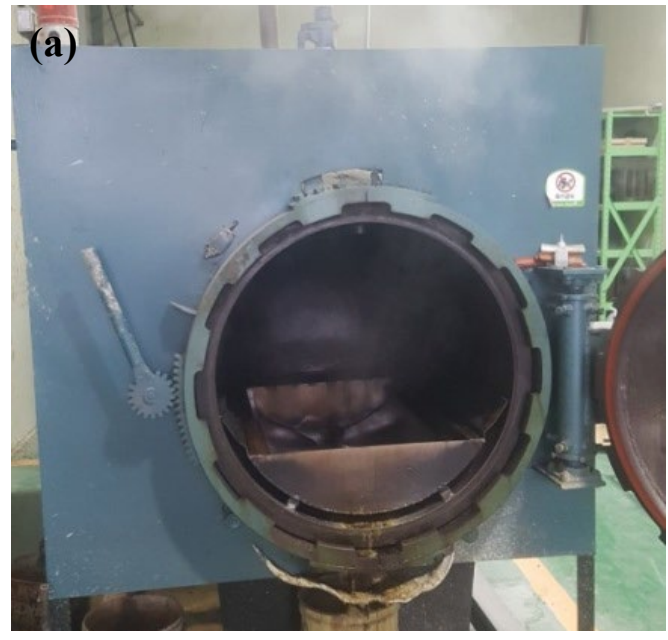

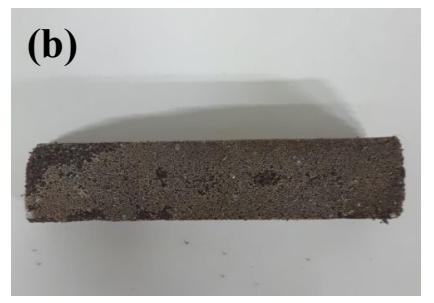

(d)

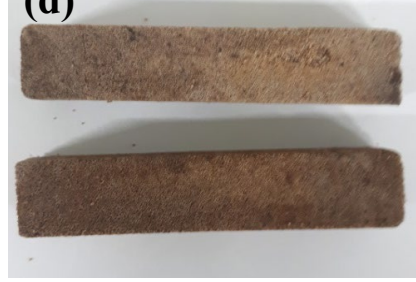

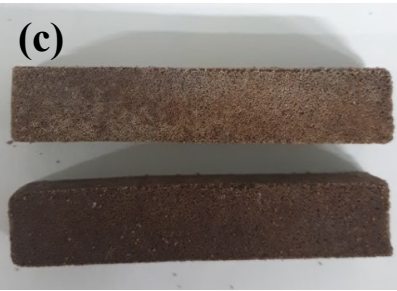

(e)

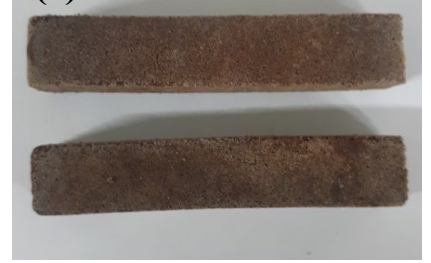

Fig. 8. Moisture-proof test in the dewaxing condition for sample type III prepared with processes A, B, C and D shown in Fig. 1.: (a) Dewaxing apparatus, (b) sample with process A, (c) sample with process B, (d) sample with process C, and (e) sample with process D. 